\title{
Family Literacy Environment and Early Literacy Development
}

\author{
John R. Kirby and Brenda Hogan \\ Queen's University
}

\begin{abstract}
A battery of reading-related and reading measures was used to select samples of good $(N=30)$ and poor readers $(N=19)$ in Grade 1. Parents of these children completed a questionnaire about current and preschool home literacy practices and socio-economic status (SES). The 2 groups were compared with t tests and in a discriminant analysis. The t tests indicated that the homes of the good and poor readers differed in many characteristics, including several aspects of home literacy, numbers of books in the home, and mothers' education. The 2 best unique discriminators of the groups were parents' teaching of letters and mothers' education. The limitations of the study and the implications are discussed.
\end{abstract}

Children's early reading development is strongly related to their later success in school (e.g., Cunningham \& Stanovich, 1997). Furthermore, many of the factors that contribute to children's standing after the first few years of schooling are known. Some of the factors concern the nature of the schooling children receive, particularly with respect to literacy instruction (National Reading Panel, 2000). Some factors are individual differences in cognitive abilities, especially those concerned with phonological processing (Kirby, Parrila, \& Pfeiffer, 2003; Torgesen, Wagner, \& Rashotte, 1994). A third set of factors concerns children's home environments. Although it is widely believed that home environments are critical in the acquisition of literacy, relatively little is known about the specific characteristics or activities in homes that support literacy development (Snow, Burns, \& Griffin, 1998). Our purpose in this study is to investigate the home literacy environment to determine which characteristics or activities distinguish the homes of later good readers from the homes of later less successful readers.

Home literacy environments may be important to children's literacy in at least three ways. First, by exposing children to books, and adults' reading, they may establish a "culture of reading," in which the skills of reading are seen as valuable and desirable. Second, home environmentthrough both literacy and oral activities - may contribute to the various pre-literacy skills, for instance phonological processing (sensitivity to, and ability to manipulate, the sounds of and within 
words), with which children enter school. Third, the home environment may provide the child with elementary literacy skills such as letter knowledge, word recognition, or word decoding. These three influences are clearly interdependent to some degree, in that elementary reading skills are unlikely to be taught without helping phonological processing, and they are more likely to be taught in a home in which literacy is valued. However, it is possible for literacy to be valued and practiced in a home without attention being paid to the enhancement of phonological processing or literacy skills. These influences are quite different in nature. The first set is broad in nature and diffuse in effect; it would be indexed by socioeconomic status, parental reading, number of books in the home, and the frequency of reading to the child. None of these factors specifically addresses the child's reading skills, but instead they provide an encouraging environment in which those skills may develop. The other two sets of factors are more specific in nature and effect: phonological processing may be fostered by rhyming or other word games and early literacy skills by specific attention to teaching letter names, letter sounds, and word recognition. We consider each of these areas in turn.

\section{The Culture of Reading: SES and Early Literacy Acquisition}

The broad home environment factors are often related to socioeconomic status (SES), which is usually measured by parental income, occupation, and/or education. It is well documented that the average reading performance of children from working class families is below that of children from middle class homes (Snow, 1993; White, 1982). Family SES has a modest but reliable association with literacy attainment, correlations usually being about .2-.3 (see Baker, Fernandez-Fein, Scher, \& Williams, 1998; Goldenberg, 2001; Leseman \& de Jong, 2001). Children from lower SES families also tend to perform worse in phonological processing tasks (Bowey, 1995; Dickinson \& Snow, 1987; Goswami, 2001; Raz \& Bryant, 1990; Wallach, Wallach, Dozier, \& Kaplan, 1977).

The SES of parents in itself, however, is an inadequate explanation of why some children are successful readers and others are not. It is difficult to see how SES could have a direct causal effect on literacy skills, in that parents of the highest SES levels do not necessarily read at home, and there is no reason why even the poorest parents cannot read to their children. Indeed, many children from working class families do become successful readers (Snow, 1993). SES is at best a "proxy" measure, representing a spectrum of many factors that may more plausibly have causal effects on reading skills. For example, Chaney (1994) found that middle class families routinely provided abundant exposure to a wide variety of literacy experiences, while the quality of literacy experiences tended to vary more among lower income and less educated families. The stereotypical view of low family SES leading to low literacy can be challenged by assessing the extent to which SES effects are due to home literacy activity effects. Unlike SES, these factors are more susceptible to change.

Amount of storybook reading at home is one of the most studied variables related to home literacy activities. Meta-analyses by Bus and van IJzendoorn (1999); Bus, van IJzendoorn, and Pellegrini (1995); and Scarborough and Dobrich (1994) have shown that frequency of reading to children at home is a good predictor of early reading achievement. Sénéchal and LeFevre (2002) found that children's storybook exposure (measured by parents' familiarity with the titles and authors of children's books) was a significant predictor of Grade 3 reading skills, but this effect disappeared after controlling for receptive language skills. They interpreted their results as suggesting that reading to children at home enhances their vocabulary and listening comprehension, which in turn contribute to reading. Frijters, Barron, and Brunello (2000) found that home literacy (reading to children, books in the home, and library visits) was associated with receptive vocabulary and letter knowledge, but that the latter effect disappeared when phonological awareness was 
controlled. Burgess, Hecht, and Lonigan (2002) also found that home literacy environment (measured by a questionnaire about family demographics, parent reading, and family storybook reading) predicted word reading at age 5-6, but that this effect was still significant, though weaker, after controlling earlier phonological sensitivity (awareness), oral language, letter knowledge, and age. These results confirm that home literacy - especially reading to children - is valuable, but indicate that its effect upon later reading ability is mediated to some extent by oral vocabulary and phonological processing.

The ambiguity concerning the effect of storybook reading on children's reading ability is that measures of storybook reading do not usually provide information about the characteristics of that reading, other than its frequency. For example, it is usually not clear whether the children are also looking at the books, and if so whether they are looking at the print or the illustrations (Evans \& Saint-Aubin, 2005). Other studies, reviewed below, indicate how storybook reading and other activities affect phonological processing and early reading skills.

\section{The Role of Phonological Processing}

There is now a vast literature indicating that phonological processing (including phonological awareness, rhyming, phonological memory, and rapid automatized naming) is critical for success in reading (e.g., Adams, 1990; Goswami \& Bryant, 1990; National Reading Panel, 2000; Snow et al., 1998). Phonological processing measures are highly predictive of later reading, whether phonological processing is assessed at school entry (e.g., Kirby et al., 2003; Torgesen et al., 1994 ) or as early as age 3 (Maclean, Bryant, \& Bradley, 1987; Scarborough, 1998). Instruction in phonological processing during the early school years is causally related to gains in reading ability (Bryant \& Bradley, 1985). One of the ways in which home environment could influence early reading skills is through the encouragement of phonological skills.

Although it is thought that phonological processing skills are to some extent the result of oral language activities in the home in the years prior to beginning school, there is less evidence to support this. Crain-Thoreson and Dale (1992) found that exposure to instruction in letter names and sounds predicted children's phonological awareness (ability to hear and manipulate phonemes in listening tasks) at age $41 / 2$. Baker et al. (1998) showed that prekindergarten rhyming activities were associated with later phonological skills. Foy and Mann (2003) demonstrated that parental teaching of reading in 4- to 6-year old children was related to the children's later phonological skills. The evidence is correlational, so it is difficult to infer causation; at least some of the effect on phonological skills is via vocabulary, letter knowledge, and speech discrimination (Foy \& Mann, 2003). Some of the home activities likely to influence development of phonological skills and therefore reading would include rhyming games; memory games; and letter activities, such as playing with magnetic letters.

\section{Early Literacy Development and the Home Environment}

It is well documented that children who are read to frequently by adults during their preschool years tend to make significantly greater progress in learning to read than children who are not read to on a regular basis (Crain-Thoreson \& Dale, 1992; Wells, 1983). Reading to children has been considered the most important activity contributing to children's success in reading (Commission on Reading, National Academy of Education, 1985). Book reading is believed to 
familiarize children with story structures, schemes, and literacy conventions which are prerequisites for understanding texts (Bus et al., 1995). Vocabulary, story understanding, definitional skill, and print knowledge of 5-year-olds have all been found to be correlated with frequent book reading to the children by their mothers (Dickinson \& Tabors, 1991). Scarborough, Dobrich, and Hager (1991) found positive correlations between the frequencies of adult reading (modeling), parent-child reading, and children's solitary book activities in the home during the preschool years and children's reading achievement in Grade 2. Frequency of story reading in the home and active participation in story reading at age 24 months were found to be significant predictors of knowledge of print conventions at age 4 1/2 (Crain-Thoreson \& Dale, 1992). Because frequency of reading to children may be associated with other factors such as SES, it is not clear how independent this effect is; for example, Evans, Shaw, and Bell (2000) found that shared book reading made no significant contribution to early reading skills after controlling parent education, and the child's age and mental ability.

More specific reading activities have been shown to be particularly important in facilitating early reading. Preschool children who were required to answer questions about letter and number names, answer questions about words, read out loud on request, answer questions about pictures in books, and carry on conversations about the pictures and text in books were found to have significantly higher literacy levels in Grade 2 than children who did not have these requirements (Scarborough et al., 1991). Crain-Thoreson and Dale (1992) found that exposure to instruction in letter names and sounds was a significant predictor of children's knowledge of print conventions and invented spelling at age 4 1/2. Evans et al. (2000); Haney and Hill (2004); Sénéchal, LeFevre, Thomas, and Daley (1998); and Sénéchal and LeFevre (2002) have shown that parents' preschool teaching of elementary reading skills (e.g., letter name and sound knowledge, word recognition) predicts subsequent reading ability, even after controlling such factors as family SES, child age, ability, oral language skills, and phonological awareness. Involving children in reading activities seems to play a critical role in early literacy acquisition.

It is not clear, however, which aspects of the home environment contribute most to early literacy. Some characteristics of the home environment may be correlated with high literacy levels in children, but may not contribute causally to the process of learning to read. For example, having many books in the home may be highly correlated with early literacy acquisition, but having numerous books in the home may simply be a characteristic of wealthy people who tend to be intelligent and tend to bear intelligent children. Having many books in the home does not contribute to literacy acquisition; it is what is done with the books that matters.

It seems that there are many potential practices which may occur in the home environment which can positively influence literacy acquisition. A possible explanation for the differences in literacy levels between children may be the presence (or lack) of literacy developing activities in the home environment. Phonological processing has been shown to be critical in the development of literacy (e.g., Adams, 1990; Torgesen et al., 1994). It seems plausible that children who have been exposed to tasks that require them to practice and develop phonological skills will be more successful in the acquisition of literacy. Although reading to children may be helpful, more focused activities, such as learning letter names and sounds (literacy instruction) and learning nursery rhymes and songs (phonological processing skills), may make a greater contribution to the development of literacy. 


\section{The Present Study}

This study compared children who differed in level of prereading (phonological processing) and early reading skill, and determined whether they also differed in their home literacy environment and socioeconomic status. We compiled a list of home environment characteristics which could potentially contribute to early literacy development. SES was estimated from the highest level of education achieved by the mother and the father of each child (Dickinson \& Snow, 1987; Wallach et al., 1977; White, 1982). We hypothesized that good and poor readers could be reliably classified when both frequency of family literacy practices and SES were used as predictors of group membership. We also sought to determine the relative contributions of home environment characteristics and SES to literacy skills. We hypothesized that family literacy environment and SES could independently discriminate between good and poor readers. Thirdly, we hypothesized that family literacy environment would be the more potent predictor, that SES would not make any significant improvement to the discrimination after accounting for family environment, but that family environment would make a significant improvement after accounting for SES. Finally, we wanted to identify which environmental factors were most important in discriminating between relatively good and poor achievers.

\section{Method}

\section{Participants}

The participants in this study were 49 Grade 1 children (20 girls, 29 boys) and their parents or guardians. The children were enrolled in six Eastern Ontario elementary schools, which were chosen to represent a broad range of social class levels, from disadvantaged to upper middle class. The children selected for this study were chosen from a larger pool of 161 participants taking part in a larger longitudinal study (all had attended kindergarten the previous year).

Selection for the present study was based on the children's performance on 12 tests of phonological processing and early reading ability. The tests were administered individually in the fall of Grade 1 (the year in which formal reading instruction began). There were two tests of each of the following: phonological memory, phonological analysis, phonological synthesis, rhyming, rapid naming, and reading. The tests for phonological memory measured serial recall of lists of words of increasing length and recall of and answering questions about nonsense sentences. The phonological analysis measures included pronunciation of a word after deletion of an indicated phoneme, and identification of the initial, middle, or final sound in a given word. The tests for phonological synthesis included pronunciation of words when given component onsets and rimes and pronunciation of words when given component phonemes. The rhyming measures included production of a rhyming word or nonword in response to a given word and recall of common nursery rhymes. Rapid naming tested the timed naming of a sequence of colours and timed naming of a sequence of pictures. The reading measures were the Woodcock (1998) Word Identification and Word Attack subtests, which assess, respectively, the identification of words shown without context and the pronunciation of pseudowords. A complete description of the measures and their sources can be found in Appendix A.

Within the sample of 161 children, there were high correlations between the measures administered to the children, and therefore a single principal component was formed. The loadings were all high (ranging from .55 to .86) and the component accounted for $50.2 \%$ of the variance in the test scores (see Appendix B). A regression factor score was formed from this first principal component 
and the children were rank ordered on it. The children were also rank ordered according to their raw score on the Word Identification reading measure (Woodcock, 1998). In order to be selected for the present study, children who were in the top or bottom thirds of the distribution of the factor score had to also be in the corresponding top or bottom half of the distribution of the Word Identification scores; this was done to ensure that there were no cases in either group with highly mismatched phonological and reading scores. We selected 42 children from the top third of the distribution of phonological processing and reading measure scores who also scored in the top half of the distribution of Word Identification scores. We selected 36 children from the bottom third of the distribution of phonological processing and reading measure scores who also scored in the bottom half of the distribution of Word Identification scores. The children were selected in this manner so that the sample would be representative of both good and poor readers.

The parents or guardians of the 78 children were asked by letter to participate in the present study. Forty-nine parents responded positively $(63 \% ; 30$ parents of good readers, 19 parents of poor readers). The parents were contacted by telephone to complete a questionnaire administered by a researcher who was unaware of the group to which the respondents' children belonged. The average age of the good readers was 77.9 months $(S D=3.3)$ and of the poor readers was 75.2 months $(S D=$ 3.2). All children came from homes in which English was the main language of communication.

\section{Materials}

The questionnaire included 12 questions that addressed the frequency of various home literacy or pre-literacy activities: 2 asked for the number of books and children's books in the home, 1 asked about the amount of adult reading in the home, and 2 asked about parent education. The activity questions asked about the frequencies of the various activities when the child was 2 to 3 years old. The frequency of each activity was measured on a 6-point scale: 0 (not at all), 1 (less than once a month), 2 (a few times a month), 3 (a few times a week), 4 (about once a day), and 5 (more than once a day). The activities listed were those shown in Table 1, plus one other (viewing of Sesame Street or similar programs, which was later discarded because of lack of variance-see below). Both the total number of books in the home and the number of children's books in the home were measured on 5-point scales; for total books, the scale points were 1 (less than 100), 2 (100199), 3 (200-299), 4 (300-500), and 5 (more than 500). For the number of children's books, the scale points were 1 (less than 25), 2 (25-50), 3 (51-100), 4 (101-200), and 5 (more than 200). Amount of adult reading was assessed on a 6-point scale: 0 (never), 1 (less than 1 hour per month), 2 (about $1 \mathrm{hr} / \mathrm{month}$ ), 3 (about $1 \mathrm{hr} /$ week), 4 (about $1 \mathrm{hr} /$ day), and 5 (more than $1 \mathrm{hr} /$ day). Level of education for each parent was measured on a 9-point scale: 1 (some elementary), 2 (completed elementary), 3 (some high school), 4 (completed high school), 5 (some community college), 6 (completed community college), 7 (some university), 8 (completed university), and 9 (professional school or graduate degree).

\section{Procedure}

A parent or guardian of each child was contacted by telephone and asked to respond to a series of questions. The parent interviews took place during February and March of the Grade 1 year. The telephone interview took approximately 10-15 minutes to complete. Of the 49 adult respondents, 46 were women and 3 were men. 


\section{Results}

\section{Comparison of Good Readers and Poor Readers}

We began by examining the distributions of each of the questionnaire variables. The frequency of Sesame Street viewing and the frequency of reading to the child at home were found to have skewed distributions (skewness values less than -1.00). The skewness in the Sesame Street distribution was due to the large number of parents who reported that their child never watched Sesame Street or other television shows in which letters and their corresponding sounds were taught. Consequently, this item was not included in further analyses. The skewness in the distribution of the frequency of reading to the child at home, however, seemed to be caused by an outlier-one child who was never read to at home. When this child was shifted from the lowest category to the third lowest, the distribution became normal but the subsequent statistical analyses did not change in significance. Therefore, the original distribution was used in the analyses. Means and standard deviations for each group (good readers and poor readers) for each family literacy practice variable measured in the questionnaire, the number of books in the home, and the SES variables can be found in Table 1.

$T$ tests were performed on the means of each of the frequency of family literacy practices variables, the number of books in the home, and the SES variables (see Table 1). Because of the possibility that multiple testing could result in the occurrence of statistically significant results by chance, only p-values of .0031 should be viewed as statistically significant (Bonferroni correction, .05 divided by 16 comparisons). According to the parents' responses, children who were good readers were read to by adults and were taught printed letters, letter sounds, and to read new words, and played memory games significantly more frequently than children who were poor readers. Parents of children who were good readers reported significantly greater total number of books in the home. The highest level of education achieved by the mothers of the good readers was significantly greater than the highest level of education received by the mothers of poor readers.

Table 1 also includes a measure of effect size for each item $(\Delta)$, which indicates how many standard deviations difference there are between the good and poor readers, expressed in $S D$ units of the poor readers. The largest effect sizes are for the three items addressing parents' teaching of letters, words, and letter sounds, followed by number of books in the home and mother's education.

\section{Discriminant Analyses}

The total number of books and the number of children's books in the home were not included in further analyses because they could not reveal any information about family literacy practices. The frequency of Sesame Street viewing was also not included as a variable in the multivariate analyses because of lack of variance. The frequency of reading to the child at home was included in the analyses, despite its skewed distribution, for reasons stated previously. To reduce multicollinearity, the frequency with which the child played with letter blocks by him or herself was not included as a variable in the discriminant function analyses because it was highly correlated with the frequency with which the child played with letter blocks with an adult. Similarly, the frequency with which the child played with magnetic letters by himself or herself was not included as a variable in the multivariate analyses because it was highly correlated with the frequency with which the child played with magnetic letters with an adult. 
Kirby \& Hogan

Table 1

Means, Standard Deviations, Number of Subjects, and T-test Results for Questionnaire Variables

\begin{tabular}{|c|c|c|c|c|c|c|c|c|c|}
\hline \multirow[b]{2}{*}{ Variables } & \multicolumn{3}{|c|}{ Good readers } & \multicolumn{3}{|c|}{ Poor readers } & \multirow[b]{2}{*}{$t$ value } & \multirow[b]{2}{*}{$p$} & \multirow[b]{2}{*}{$\Delta$} \\
\hline & $M$ & $S D$ & $N$ & $M$ & $S D$ & $N$ & & & \\
\hline \multicolumn{10}{|l|}{ Frequency variables } \\
\hline Read to at home & 4.07 & 0.58 & 30 & 3.37 & 0.96 & 19 & 3.18 & 0.003 & 0.73 \\
\hline Taught new words & 3.07 & 1.68 & 30 & 2.74 & 1.56 & 19 & 0.60 & 0.495 & 0.21 \\
\hline Nursery rhymes/songs & 3.10 & 1.94 & 30 & 2.21 & 1.40 & 19 & 2.49 & 0.016 & 0.64 \\
\hline Memory games & 2.37 & 1.27 & 30 & 1.16 & 1.21 & 19 & 3.30 & 0.002 & 1.00 \\
\hline Magnetic letters (child) & 2.28 & 1.31 & 29 & 1.73 & 1.33 & 19 & 1.51 & 0.138 & 0.41 \\
\hline Magnetic letters (adult) & 2.24 & 1.06 & 29 & 1.42 & 1.12 & 19 & 2.57 & 0.014 & 0.73 \\
\hline Letter blocks (child) & 1.48 & 1.41 & 29 & 1.72 & 1.36 & 18 & -0.57 & 0.569 & -0.18 \\
\hline Letter blocks (adult) & 1.34 & 1.26 & 29 & 1.50 & 1.20 & 18 & -0.42 & 0.678 & -0.13 \\
\hline Taught printed letters & 2.93 & 1.23 & 30 & 0.74 & 0.99 & 19 & 6.55 & $<0.001$ & 2.21 \\
\hline Taught letter sounds & 2.17 & 1.66 & 30 & 0.47 & 0.96 & 19 & 4.02 & $<0.001$ & 1.77 \\
\hline Taught to read words & 2.27 & 1.55 & 30 & 0.33 & 0.77 & 18 & 4.92 & $<0.001$ & 2.52 \\
\hline Adult reading & 3.13 & 1.04 & 30 & 3.10 & 0.94 & 19 & 0.10 & 0.924 & 0.03 \\
\hline \multicolumn{10}{|l|}{ Number of books } \\
\hline Total books & 3.27 & 1.20 & 30 & 1.79 & 1.03 & 19 & 4.42 & $<0.001$ & 1.44 \\
\hline Children's books & 2.83 & 0.91 & 30 & 2.21 & 0.98 & 19 & 2.27 & 0.028 & 0.63 \\
\hline \multicolumn{10}{|l|}{ Social class variables } \\
\hline Mother's education & 6.70 & 1.49 & 30 & 5.06 & 1.31 & 18 & 3.87 & $<0.001$ & 1.25 \\
\hline Father's education & 6.70 & 1.97 & 30 & 5.56 & 1.50 & 18 & 2.12 & 0.039 & 0.76 \\
\hline
\end{tabular}

Note: N's vary because of missing data.

Three discriminant analyses were performed. The first analysis was performed to determine the classification hit rate when both family literacy environment variables and SES variables were used as predictors of group membership. A second analysis determined how successful SES variables alone would be as predictors of group membership. A third analysis was performed to assess the classification hit rate of the family literacy environment variables alone.

Discriminant analysis allowed for the determination of the classification hit rate when using the frequency of family literacy variables and SES variables as predictors of group membership. Of the original 49 cases, 5 were dropped from this analysis because of missing data. Missing data appeared to be randomly scattered throughout the groups and variables. The standardized canonical discriminant function coefficients and the pooled within-groups correlations between the variables and the canonical discriminant functions can be found in Table 2. The standardized canonical 
discriminant function coefficients demonstrate that when all other variables are held constant, teaching printed letters and maternal education level have strong predictive value. The family literacy practices variables and the social class variables differentiated significantly between good and poor readers, $\Lambda=0.32, \chi^{2}(12)=41.58, p<.001$; the classification hit rate was $88.64 \%$ (Table 3 ). This supports the hypothesis that good and poor readers can be reliably classified when both family literacy practices variables and SES variables are used as predictors.

Table 2

Results of Discriminant Analysis of Family Literacy Practices and Social Class Variables

\begin{tabular}{lcc}
\hline Predictor variable & $\begin{array}{c}\text { Standardized canonical } \\
\text { discriminant function } \\
\text { coefficients }\end{array}$ & $\begin{array}{c}\text { Correlation between variable } \\
\text { and the function }\end{array}$ \\
\hline Family literacy practices & 1.04 & 0.61 \\
Taught printed letters & 0.39 & 0.49 \\
Taught to read words & -0.25 & 0.37 \\
Taught letter sounds & 0.01 & 0.33 \\
Memory games & -0.27 & 0.29 \\
Read to at home & 0.01 & 0.22 \\
Magnetic letters (adult) & -0.24 & 0.16 \\
Nursery rhymes/songs & -0.12 & 0.03 \\
Taught new words & -0.37 & -0.01 \\
Adult reading & -0.28 & -0.01 \\
Letter blocks (adult) & & 0.39 \\
Social class variables & 0.94 & 0.17 \\
Maternal education level & -0.07 & \\
Paternal education level &
\end{tabular}

Canonical $\mathrm{R}=0.83$

Table 3

Discriminant Function Analysis of Good and Poor Readers Using Social Class Variables and Family Literacy Practices Variables as Predictors of Group Membership

\begin{tabular}{lccc}
\hline & & \multicolumn{2}{c}{ Predicted group membership } \\
\cline { 3 - 4 } & $N$ & Good readers & Poor readers \\
\hline Good readers & 28 & $26(92.9 \%)$ & $2(7.1 \%)$ \\
Poor readers & 16 & $3(18.8 \%)$ & $13(81.3 \%)$ \\
\hline
\end{tabular}

Percent of cases correctly classified: $88.64 \%$ 
A second discriminant analysis was performed to determine the classification hit rate when only the SES variables were used as predictors of group membership. Of the original 49 cases, one was excluded because of missing data, leaving 48 cases (30 good readers, 18 poor readers). The standardized canonical discriminant function coefficients and the pooled within-groups correlations between the variables and the canonical discriminant functions are shown in Table 4. Maternal education level had much stronger predictive value than paternal education level. The social class variables could significantly discriminate between the groups, $\Lambda=0.75, \chi^{2}(2)=12.98, p<.005$; the classification hit rate was $77.08 \%$ (Table 5). Using only the SES variables as predictors allowed for effective discrimination between good and poor readers.

Table 4

Results of Discriminant Analysis of Social Class Variables: Standardized Canonical Discriminant Function Coefficients and Pooled Within-Groups Correlations Between the Variables and the Canonical Discriminant Function

\begin{tabular}{lcc}
\hline Predictor variable & $\begin{array}{c}\text { Standardized canonical } \\
\text { discriminant function } \\
\text { coefficients }\end{array}$ & $\begin{array}{c}\text { Correlations between the } \\
\text { variables and the function }\end{array}$ \\
\hline Social class variables & 1.13 & 0.99 \\
Maternal education level & -0.21 & 0.54 \\
Paternal education level & & \\
\hline
\end{tabular}

Canonical $\mathrm{R}=0.50$

Table 5

Discriminant Function Analysis of Good and Poor Readers Using Social Class Variables as Predictors of Group Membership

\begin{tabular}{lccc}
\hline & & \multicolumn{2}{c}{ Predicted group membership } \\
\cline { 3 - 4 } & $N$ & Good readers & Poor readers \\
\hline Good readers & 30 & $26(86.7 \%)$ & $4(13.3 \%)$ \\
Poor readers & 16 & $7(38.9 \%)$ & $11(61.1 \%)$ \\
\hline
\end{tabular}

Percent of cases correctly classified: $77.08 \%$ 
The third discriminant analysis determined the classification hit rate when using only the family literacy practices variables as predictors of group membership. Four cases were eliminated from the original 49 because of missing data. Of the remaining 45 cases, 28 were good readers and 17 were poor readers. The standardized canonical discriminant function coefficients and the pooled within-groups correlations between the variables and the canonical discriminant functions are in Table 6. Teaching the child printed letters and to read new words emerged as strong predictors of group membership. The family literacy practices variables could significantly discriminate between the groups, $\Lambda=0.46, \chi^{2}(10)=29.58, p<.005$; the classification hit rate was $84.44 \%$ (Table 7 ). This supports the importance of family literacy practices as predictors of group membership. Because Wilks' Lambda represents the proportion of variance not explained by the predictors, 1 Wilks' Lambda represents the proportion of variance explained, which is analogous to the $\mathrm{R}^{2}$ value calculated in multiple regression (Tatsuoka, 1971). Therefore, the change in Wilks' Lambda can be calculated in the same manner that an increment in $\mathrm{R}^{2}$ is determined (Pedhazur, 1973). This procedure was followed to determine whether family literacy variables made an additional significant contribution to the prediction of early reading ability when SES was controlled, and again to determine whether SES made a significant contribution to the prediction of early reading ability when family literacy variables were controlled.

There was a significant decrease in Wilks' Lambda when the SES variables were included in the analysis, $F(2,29)=7.06, p<.001$. This indicates that the SES variables significantly improved the classification of good and poor readers. Similarly, there was a significant change in Wilks' Lambda, $F(10,29)=3.77, p<.001$, indicating that classification of good and poor readers improved with the addition of family literacy practices variables as predictors.

Table 6

Results of Discriminant Analysis of Family Literacy Practices Variables: Standardized Canonical Discriminant Function Coefficients and Pooled Within-Groups Correlations Between the Variables and the Canonical Discriminant Function

\begin{tabular}{lcc}
\hline Predictor variable & $\begin{array}{c}\text { Standardized canonical } \\
\text { discriminant function } \\
\text { coefficients }\end{array}$ & $\begin{array}{c}\text { Correlations between the } \\
\text { variables and the function }\end{array}$ \\
\hline Family literacy practices & 0.58 & 0.84 \\
Taught printed letters & 0.43 & 0.69 \\
Taught to read words & 0.03 & 0.52 \\
Taught letter sounds & 0.23 & 0.41 \\
Read to at home & 0.13 & 0.41 \\
Memory games & 0.11 & 0.33 \\
Magnetic letters (adult) & 0.03 & 0.27 \\
Nursery rhymes/songs & -0.11 & -0.03 \\
Adult reading & -0.07 & 0.02 \\
Taught new words & -0.06 & -0.01 \\
Letter blocks (adult) & & \\
\hline
\end{tabular}

Canonical $\mathrm{R}=0.74$ 
Table 7

Discriminant Function Analysis of Good and Poor Readers Using Family Literacy Practices Variables as Predictors of Group Membership

\begin{tabular}{lccc}
\hline & & \multicolumn{2}{c}{ Predicted group membership } \\
\cline { 3 - 4 } & $N$ & Good readers & Poor readers \\
\hline Good readers & 28 & $26(92.9 \%)$ & $2(7.1 \%)$ \\
Poor readers & 17 & $5(29.4 \%)$ & $11(70.6 \%)$ \\
\hline
\end{tabular}

Percent of cases correctly classified: $84.4 \%$

\section{Discussion}

The purpose of this study was to investigate the characteristics of the home that best discriminate later good readers from later less successful readers. To do this, we evaluated the relative contributions of a variety of aspects of the family literacy environment and SES to early reading development. Perhaps not surprisingly, our first hypothesis, that the homes of the good and poor readers could be discriminated, was supported. The combination of family environment and SES variables was successful in classifying over $88 \%$ of the children. The homes of the good and poor readers differed in many characteristics, including several aspects of home literacy, numbers of books in the home, and mothers' education (see Table 1). More interesting is that parents' teaching of letters and mothers' education were the two best unique discriminators (Table 2). The main implications of this finding, that literacy environment and SES make independent contributions and that the most important aspect of the literacy environment is the teaching of reading skills, were confirmed by subsequent analyses. The second hypothesis, that either set of variables could discriminate between the groups, was also supported. Our third hypothesis, however, was not supported. We had hypothesized that the family literacy environment effects would overwhelm the SES effects, leaving SES with no unique effect. Instead, it was clear that both family environment and SES made independent contributions.

We had hypothesized that any differences in literacy level observed between children from high and low socioeconomic backgrounds would be accounted for by the frequency of literacy developing practices in the home. This hypothesis was based on the argument that SES is a proxy variable, only powerful because it stands in for the variables that have causal effects. We argued that it was more likely to be the aspects of the home literacy environment, such as reading to children, which would have the more powerful effects. The results of the present study, however, did not support this hypothesis. We found that family literacy practices and SES were both important in discriminating between good and poor readers. However, this finding can be explained by the fact that it was the level of education of the mother which emerged as a substantial predictor of group membership. In many families, the education level of the father is a better indicator of social class or status (Statistics Canada, 1993, 1994). In relatively traditional families, it is the mother who is more involved in the early reading activities of the children. Hence, the finding that the education level of the mother contributes substantially to the discrimination between good and poor readers is not surprising and may reflect further aspects of early literacy practices more than social class. Chaney (1994) found that while other socioeconomic factors played a nonsignificant role in predicting phonological awareness and early pre-reading ability in 3-year-old children, maternal education had 
predictive value for specific phonological tasks. Mothers' education may also work more broadly in establishing a deeper "culture of literacy" in the home.

Our second focus was to determine which aspects of the family literacy environment have the greatest effect in discriminating between the homes of later successful and less successful readers. We assessed the effects of a broad range of characteristics, including amount of adult reading, amount of reading to the child, oral language activities (such as memory games), and direct teaching of literacy. The clear result, shown in the $t$-test and discriminant analyses, is that it was the direct teaching of reading skills that had the greatest effect.

The finding that family environment and SES, either separately or in combination, could discriminate between later successful and less successful early readers was consistent with the vast majority of the literature reviewed earlier in this paper (e.g., Baker et al., 1998; Burgess et al., 2002; Bus et al., 1995; Crain-Thoreson \& Dale, 1992; Evans et al., 2000; Haney \& Hill, 2004; Scarborough et al., 1991; Snow, 1993). We were more interested to determine the relative effects of family environment and SES, and then to identify which aspects of family environment were most predictive. Although family literacy practices were more successful than SES in discriminating between good and poor readers (84\% vs. $77 \%)$, the difference was not great. Perhaps more important is that the family literacy practices items suggest more ways to help families than do the SES measures.

The aspects of the home environment that carried the most weight in discriminating between the homes of the more and less successful readers were those involving the teaching of basic literacy skills. Other activities, such as playing memory games or playing with magnetic letters, either emerged in the $t$ tests or were correlated with the discriminant function, but did not contribute uniquely. Amount of adult reading in the home had little effect. Perhaps most importantly, amount of reading to the child had a weak effect and one that was not unique.

This finding that there are measures that correlate with the dimension that best discriminates between the homes of good and poor readers without making a unique contribution to it, indicates that these aspects overlap with the more successful discriminators; they may be part of the successful home environment, but they do not make a significant contribution by themselves. It would be wrong to conclude that these overlapping aspects are unimportant. For the other aspects, those that neither contributed uniquely nor correlated with the discrimination, the interpretation is less certain. The only mean differences that favoured the poor readers (playing with letter blocks, with and without adults) were very small, resulting in very small negative correlations with the discriminant function. There is certainly no sign here of activities to avoid. It is also important to understand that these results apply to this sample given its background and experience. Any of the home activities might become a positive contributor if carried out differently. Our results say more about what should be encouraged than what should be discouraged.

The nature of the literacy practices variables which emerged as important predictors of early reading ability has important implications. Activities which focused on direct literacy instruction were associated with high reading levels. Hence, increasing the frequency of activities, such as teaching printed letters and to read new words, during the preschool years may facilitate early literacy acquisition. Increasing the occurrence of other activities, such as playing memory games, may also help phonological learning and literacy acquisition. Although these activities require the time and participation of the parent or guardian, they can easily be implemented in many households. Many of the literacy activities mentioned in the present study, however, do require parental literacy. Maternal education level was a significant predictor of early reading ability which cannot be easily improved. However, increasing the frequency of family literacy practices may serve as a protective factor against the influence of social class. 
There are certain limitations to the present study that need to be acknowledged. First consider reliability and validity. We do not have reliability estimates either in terms of test-retest reliability or internal consistency reliability. It is possible, for instance, that the parents would have answered the questions differently if asked at a later time. Internal consistency reliability did not make sense to assess because we posed the questions to measure distinct features of the home environment and we had no reason to expect those who, for instance, sang nursery rhymes to their children would also encourage them to play with magnetic letters. The question regarding validity is whether parents responded to the questions accurately. Although this study demonstrated that information about early literacy practices collected from telephone interviews can predict early reading ability, the data on the frequency of family literacy practices were self-reported and retrospective. Social desirability may have confounded the estimation of the frequency of reading activities, and this bias may have been systematically different between the groups. However, in this study it is important to remember that many plausibly-important family literacy practices (e.g., reading to children) did not emerge as powerful discriminators, so it seems unlikely that social desirability is the main cause of the results. Future research could use direct observation as a method of controlling possible effects of social desirability, but this is likely to be cumbersome and intrusive.

The present study had a modest response rate. The response rate was lower for the parents of poor readers $(52.7 \%)$ than for parents of good readers $(71.4 \%)$. It is possible that parents of poor readers were more hesitant than the parents of good readers to participate in a study which examined literacy practices in the home. The concern here is that the sample of parents of poor readers may not have been representative. For example, the parents of the poor readers in this study had higher levels of education (see Table 1) than expected, indicating on average that they had completed some community college (as opposed to the university education of the parents of the more able readers). If it was the less educated parents of poor readers who declined to participate, this would have tended to weaken the differences between groups. The fact that significant and meaningful differences were obtained suggests either that the sampling problem was not too great or that the results would have been even stronger with the inclusion of a more representative sample.

There are undoubtedly other aspects of the home environment which contribute to early literacy acquisition which were not measured in this study. For example, the present study showed that children who were read to frequently by adults during their preschool years demonstrated higher reading levels than children who were read to less frequently. The nature of "shared reading," however, may be very important in determining the effectiveness of reading to a child. Pointing to words, asking questions, and involving the child in the reading process may increase the quality of time spent reading to the child, consequently improving early reading development. Attitudinal aspects of the home environment may also be related to differences in reading ability of young children. A child who has the desire to learn to read and is interested in literacy-related activities may be more likely to elicit more or better reading activities from the parent. Hence, the attitude of the child may influence the frequency of family literacy practices. Observational studies could investigate whether these and other aspects of the home environment contribute to early literacy acquisition.

What are the implications of these results for the poor readers? It is important to acknowledge that the results of this study are correlational, as are the results of most studies in this area. Firm conclusions will have to await causal, experimental studies. However, we see two broad areas of implication. First, kindergarten and Grade 1 teachers need to recognize that these poor readers begin not only with less experience with reading, but also with less direct exposure to the mechanics of reading; as many authors have argued (e.g., Adams, 1990), they need increased and intensive instruction in these mechanics. Second, parents should be advised about how to conduct home 
reading with their preschoolers. Simply reading to children is not enough. It is important to engage them, direct their attention to key features of text (cf. Evans \& Saint-Aubin, 2005), and introduce them to the mechanics of reading.

\section{References}

Adams, M. J. (1990). Beginning to read: Thinking and learning about print. Cambridge, MA: MIT Press.

Baker, L., Fernandez-Fein, S., Scher, D., \& Williams, H. (1998). Home experiences related to the development of word recognition. In J. L. Metsala \& L. C. Ehri (Eds.), Word recognition in beginning literacy (pp. 263-287). Mahwah, NJ: Erlbaum.

Bowey, J. A. (1995). Socioeconomic status differences in preschool phonological sensitivity and firstgrade reading achievement. Journal of Educational Psychology, 87, 476-487.

Bryant, P., \& Bradley, L. (1985). Children's reading problems: Psychology and education. New York: Oxford University Press.

Burgess, S. R., Hecht, S. A., \& Lonigan, C. J. (2002). Relations of the home literacy environment (HLE) to the development of reading-related abilities: A one-year longitudinal study. Reading Research Quarterly, 37, 408-426.

Bus, A. G., \& van IJzendoorn, M. H. (1999). Phonological awareness and early reading: A meta-analysis of experimental training studies. Journal of Educational Psychology, 91, 403-414.

Bus, A. G., van IJzendoorn, M. H., \& Pellegrini, A. D. (1995). Joint book reading makes for success in learning to read: A meta-analysis on intergenerational transmission of literacy. Review of Educational Research, 65, 1-20.

Chaney, C. (1994). Language development, metalinguistic awareness, and emergent literacy skills of 3 year-old children in relation to social class. Applied Psycholinguistics, 15, 371-394.

Commission on Reading, National Academy of Education. (1985). Becoming a nation of readers. Washington, DC: National Institute of Education.

Crain-Thoreson, C., \& Dale P. S. (1992). Do early talkers become early readers? Linguistic precocity, preschool language, and emergent literacy. Developmental Psychology, 28, 421-429.

Cunningham, A. E., \& Stanovich, K. E. (1997). Early reading acquisition and its relation to reading experience and ability ten years later. Developmental Psychology, 33, 934-945.

Dickinson, D. K., \& Snow, C. E. (1987). Interrelationships among prereading and oral language skills in kindergarteners from two social classes. Early Childhood Research Quarterly, 2, 1-25.

Dickinson, D. K., \& Tabors, P. O. (1991). Early literacy: Linkages between home, school and literacy achievement at age five. Journal of Research in Childhood Education, 6, 30-43.

Evans, M. A., \& Saint-Aubin, J. (2005). What children are looking at during shared storybook reading: Evidence from eye movement monitoring. Psychological Science, 16, 913-920.

Evans, M. A., Shaw, D., \& Bell, M. (2000). Home literacy activities and their influence on early literacy skills. Canadian Journal of Experimental Psychology, 54, 65-75.

Foy, J. G., \& Mann, V. (2003). Home literacy environment and phonological awareness in preschool children: Differential effects for rhyme and phoneme awareness. Applied Psycholinguistics, 24, 59-88.

Frijters, J. C., Barron, R. W., \& Brunello, M. (2000). Direct and mediated influences of home literacy and literacy interest on pre-readers' oral vocabulary and early writen language skill. Journal of Educational Psychology, 92, 466-477.

Goldenberg, C. (2001). Making schools work for low-income families in the $21^{\text {st }}$ century. In S. B. Neuman \& D. K. Dickinson (Eds.), Handbook of early literacy research (pp. 211-231). New York: Guilford Press. 
Goswami, U. (2001). Early phonological development and the acquisition of literacy. In S. B. Neuman \& D. K. Dickinson (Eds.), Handbook of early literacy research (pp. 111-125). New York: Guilford Press.

Goswami, U., \& Bryant, P. (1990). Phonological skills and learning to read. London: Erlbaum.

Haney, M., \& Hill, J. (2004). Relationships between parent-teaching activities and emergent literacy in preschool children. Early Childhood Development and Care, 173, 215-228.

Kirby, J. R., Parrila, R., \& Pfeiffer, S. (2003). Naming speed and phonological processing as predictors of reading development. Journal of Educational Psychology, 95, 453-464.

Leseman, P. P. M., \& de Jong, P. F. (2001). How important is home literacy for acquiring literacy in school? In L. T. Verhoeven \& C. E. Snow (Eds.), Literacy and motivation: Reading engagement in individuals and groups (pp. 71-93). Mahwah, NJ: Erlbaum.

Maclean, M., Bryant, P., \& Bradley, L. (1987). Rhymes, nursery rhymes, and reading in early childhood. Merrill - Palmer Quarterly, 33, 255-281.

Naglieri, J. A., \& Das, J. P. (1997). Das-Naglieri: Cognitive Assessment System interpretive handbook. Itasca, IL: Riverside.

National Reading Panel. (2000). Teaching children to read: An evidence based assessment of the scientific literature on reading and its implications for reading instruction. Bethesda, MD: National Institute of Child Health and Human Development.

Pedhazur, E. J. (1973). Multiple regression in behavioural research. New York: Holt, Rinehart, \& Winston.

Raz, I. S., \& Bryant, P. E. (1990). Social background, phonological awareness, and children's reading. British Journal of Developmental Psychology, 8, 209-226.

Scarborough, H. S. (1998). Early identification of children at risk for reading disabilities: Phonological awareness and some other promising predictors. In B. K. Shapiro, P. J. Accardo, \& A. J. Capute (Eds.), Specific reading disability: A view of the spectrum (pp. 75-119). Timonium, MD: York Press.

Scarborough, H. S., \& Dobrich, W. (1994). On the efficacy of reading to preschoolers. Developmental Review, 14, 245-302.

Scarborough, H. S., Dobrich, W., \& Hager, M. (1991). Preschool literacy experience and later reading achievement. Journal of Learning Disabilities, 24, 508-511.

Sénéchal, M., \& LeFevre, J. (2002). Parental involvement in the development of children's reading skills: A five-year longitudinal study. Child Development, 73, 445-460.

Sénéchal, M., LeFevre, J., Thomas, E. M., \& Daley, K. E. (1998). Differential effects of home literacy experiences on the development of oral and written language. Reading Research Quarterly, 33, 96-116.

Snow, C. E. (1993). Families as social contexts for literacy development. In C. Daiute (Ed.), The development of literacy through social interaction (pp. 11-24). San Francisco: Jossey-Bass Publishers.

Snow, C. E., Burns, M. S., \& Griffin, P. (1998). Preventing reading difficulties in young children. Washington, DC: National Academy Press.

Statistics Canada. (1993). Characteristics of dual-earner families. (Catalogue No. 13-215). Ottawa, ON: Statisitics Canada.

Statistics Canada (1994). Earnings of men and women. (Catalogue No. 13-217). Ottawa, ON: Statistics Canada.

Tatsuoka, M. M. (1971). Multivariate analysis: Techniques for educational and psychological research. New York: John Wiley \& Sons, Inc.

Torgeson, J. K., Wagner, R. K., \& Rashotte, C. A. (1994). Longitudinal studies of phonological processing and reading. Journal of Learning Disabilities, 27, 276-286. 
Wallach, L., Wallach, M. A., Dozier, M. G., \& Kaplan, N. W. (1977). Poor children learning to read do not have trouble with auditory discrimination but do have trouble with phoneme recognition. Journal of Educational Psychology, 69, 36-39.

Wells, G. (1983). Language and learning in the early years. Early Child Development and Care, 11, 69-77.

White, K. R. (1982). Socioeconomic status and academic acheivement. Psychological Bulletin, 91, 461-481.

Wolf, M., Bally, H., \& Morris, R. (1986). Automaticiy, retrieval processes and reading: A longitudinal study in average and impaired readers. Child Development, 57, 988-1000.

Woodcock, R. W. (1998). Woodcock Reading Mastery Tests-Revised (WRMT-R): Forms G \& H. USA: American Guidance Service.

\section{Authors' Note}

Correspondence concerning this article should be addressed to John R. Kirby, Faculty of Education, Queen's University, Kingston, ON, Canada K7L 3N6. E-mail: john.kirby@queensu.ca Brenda Hogan is now a clinical psychologist at Back in Motion, Vancouver, BC, Canada.

This research was supported by a grant from the Social Sciences and Humanities Research Council of Canada. The authors thank Richard Wagner for providing some test materials; Jennifer Dawson for her comments on an earlier version of the paper; and the children, parents, and schools for their participation.

\section{Appendix A \\ Description of Measures Administered to all Child Participants}

\section{Phonological Analysis Tasks}

Sound Isolation (Wagner, Torgesen, \& Rashotte, 1994). A word is presented orally to the child and the child is asked to identify either the first, middle, or last sound in that word. If the child does not understand the concepts of first, middle, and last, an analogy is provided. All words presented have one syllable. Six demonstration items are followed by 15 test items.

Phoneme Elision (Wagner et al., 1994). A whole word is presented orally to the child. The child is asked what the resulting sound would be when an identified sound is removed. The identified sound could be the first, middle, or last sound in the word. There are 4 demonstration items and 15 test items, with one and two syllable words.

\section{Phonological Synthesis Tasks}

Blending Onset-Rime (Wagner et al., 1994). A word is presented orally to the child in small parts. The child is asked to listen carefully so that he/she can put the parts together and say the word. The test is presented as isolated pairs of onsets (the initial consonant or consonant cluster) and rimes (the remaining vowels and consonants). There are 6 demonstration items and 15 test items. Each item is a single syllable word with three to five phonemes.

Blending Phonemes (Wagner et al., 1994). Words are presented to the child phoneme by phoneme. The items consist of one and two syllable words with two to six phonemes. The child is asked to pronounce the word that results when the phonemes are blended together. There are 6 demonstration items and 15 test items. 


\section{Phonological Memory Tasks}

Word Series (Naglieri \& Das, 1997). In this test, single syllable words are presented in series ranging in length from two to nine words. The words are selected from a selection of nine words (key, book, shoe, dog, man, girl, cow, car, wall). The test starts with series containing two words and builds to series containing nine words. Words are presented orally at a rate of one per second. The subject must repeat each series in the order in which it was presented. There is a total of 26 test items.

Sentence Repetition and Questions (Naglieri \& Das, 1997). The child is asked to repeat sentences that use colour words in place of nouns/verbs (e.g., The blue is graying). There are 2 sample items and 21 test items. The same sentences are then presented again, but instead of repeating, the child listens and is asked a specific question about the sentence. For example, "The blue is yellowing. What is yellowing?" is one of the two sample items. In addition to the sample items there are 15 test items.

\section{Rhyming Ability Tasks}

Nursery Rhyme Knowledge (adapted from Maclean, Bryant, \& Bradley, 1987). The child is asked if he or she knows one of four nursery rhymes by title. If the child responds positively, he or she is asked to recite it for the researcher. If it is indicated that the child does not know the nursery rhyme, the researcher starts reciting it, pausing at the end of each line to verify that it does not sound familiar to the child. Upon hearing the start of the rhyme, if the child realizes that he or she does know the rhyme, he or she is asked to continue and finish reciting it.

Rhyme Production (adapted from Maclean et al., 1987). The child is informed that words that rhyme are words that sound alike. He/she is given two examples (e.g., "cat and hat") and asked to suggest another rhyming word for each pair. The child is asked to produce a rhyme for each of five words.

\section{Rapid Naming Ability Tasks}

Colour Naming (adapted from Wolf, Bally, \& Morris, 1986). The child is shown a page which has four blocks of colour in a row: red, blue, green, and yellow. The child is asked to identify each one. This page serves as a check that the child can identify the colour names. The demonstration page consists of two rows of four colours, each occurring only once in a row. The child is asked to name the colours from left to right as quickly as possible. The test consists of 32 items. There are two pages, each containing four rows of four colours. Each colour occurs only once in each row and in each column. The child is asked to name the colours from left to right as quickly as possible.

Picture Naming (adapted from Wolf et al., 1986). This test was constructed to be identical to the Colour Naming test except that the stimuli are four pictures of animals: horse, cat, bird, and pig. There is a demonstration task with 8 items followed by a 32 -item test.

\section{Reading Measures}

The Woodcock Reading Mastery Tests-Revised, Form G, subtests Word Identification and Word Attack (Woodcock, 1998) were administered. The Word Identification subtest requires the child to read words which become progressively more difficult, one syllable to multi-syllabic. The Word Attack subtest measures analytic and decoding skills. The child is asked to read aloud nonsense syllables. Administration of both tests ends after the child has made four consecutive errors. 


\section{Appendix B}

Principal Component Loadings for the Ten Phonological Processing and Two Reading Tests $(N=161)$.

\begin{tabular}{lc} 
Measure & Component loading \\
\hline Phonological processing tests & 0.555 \\
Word series & 0.694 \\
Sentence repetition and questions & 0.621 \\
Rhyme production & 0.754 \\
Nursery rhyme knowledge & 0.723 \\
Blending phonemes & 0.700 \\
Blending onset-rime & 0.848 \\
Phoneme elision & 0.865 \\
Sound isolation & -0.618 \\
Colour naming & -0.602 \\
Picture naming & \\
Reading measures & 0.699 \\
Word attack & 0.755 \\
Word identification & \\
\hline
\end{tabular}

Total variance explained: $50.2 \%$ 